\title{
Jacques-Olivier Boudon (dir.), De l'École française de Rome au Journal La Croix. Jean Guiraud, polémiste chrétien
}

Rome, École française de Rome, 2014, 421 p.

\section{Frédéric Gugelot}

\section{OpenEdition \\ Journals}

Édition électronique

URL : http://journals.openedition.org/assr/27317

DOI : $10.4000 /$ assr. 27317

ISSN : $1777-5825$

Éditeur

Éditions de l'EHESS

Édition imprimée

Date de publication : 1 octobre 2015

Pagination : 269

ISBN : 978-2-7132-2515-4

ISSN : 0335-5985

\section{Référence électronique}

Frédéric Gugelot, « Jacques-Olivier Boudon (dir.), De l'École française de Rome au Journal La Croix. Jean Guiraud, polémiste chrétien », Archives de sciences sociales des religions [En ligne], 172 I octobredécembre, mis en ligne le 18 mai 2016, consulté le 24 septembre 2020. URL : http://

journals.openedition.org/assr/27317; DOI : https://doi.org/10.4000/assr.27317 


\section{Jacques-Olivier Boudon (dir.), De l'École française de Rome au Journal La Croix. Jean Guiraud, polémiste chrétien}

Rome, École française de Rome, 2014, 421 p.

Frédéric Gugelot

\section{RÉFÉRENCE}

Jacques-Olivier Boudon (dir.), De l'École française de Rome au Journal La Croix. Jean Guiraud, polémiste chrétien, Rome, École française de Rome, 2014, 421 p. 
1 Issu d'un colloque de 2006, fondé sur l'achèvement du classement aux Archives nationales des papiers de Jean Guiraud, l'ouvrage de 400 pages nous livre en dix articles les différentes facettes de ce professeur, historien, journaliste et militant chrétien de la première moitié du $\mathrm{xx}^{\mathrm{e}}$ siècle. L'ensemble suit un ordre chronologique.

2 Issu d'un milieu modeste, Jean Guiraud réalise une réelle ascension sociale grâce à l'école publique. Né en 1866, il appartient à la génération qui a grandi dans le souvenir de la défaite de 1870 . Il a reçu une éducation marquée par une morale austère, une discipline de fer. Il est formé par un père veuf, dont l'engagement en faveur de ses fils est admirable et qui leur inculque que « La religion bien comprise,

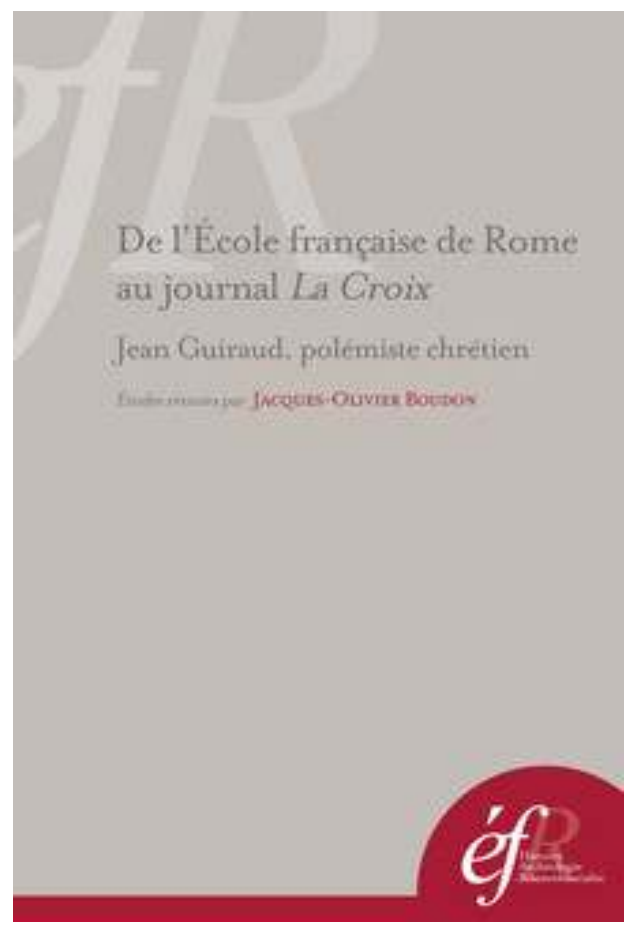
bien entendue est une excellente chose, elle ne nous apprend qu'à faire le bien. L'Évangile est sans contredit le premier code de morale du monde.» (p. 24 et p. 47) "Jean Guiraud appartient à une nouvelle génération, celle qui allait exposer ses doutes dans les capacités de la science à expliquer le monde et à fonder une morale. » (p. 36). Pour Guiraud, la République se fonde sur une idéologie antichrétienne (p.51), il déploie son engagement dans la défense des valeurs religieuses autour de l'éducation, de la famille et de l'Église. Membre de la Conférence de Saint-Vincent-de-Paul (p. 247), il est un des plus actifs «tala » à l'ENS. Un de ses proches camarades de Rome, Romain Rolland, le définit comme « un catholique passionné » (p. 84). «Tu as une trop forte tendance à ne voir toujours les choses et les événements qu'à travers le prisme de la religion », lui écrit son père en 1891.

3 Entre amitiés juvéniles et découvertes de l'Italie, l'École française de Rome, évoquée pendant une majeure partie du volume, apparaît, pour ses forts en thème latin et autres, comme un moment studieux mais aussi de découvertes, ancrées dans une sociabilité amicale et savante, particulièrement ecclésiale pour le jeune homme. Guiraud y exprime une piété profonde, un intérêt passionné pour la vie de l'Église, pour l'histoire ancienne et médiévale de la Rome pontificale (p.139) mais montre peu d'attention pour l'actualité politique et culturelle italienne. Son séjour à Rome aboutit à une inflexion de ses recherches, il y devient médiéviste et approfondit sa foi et son catholicisme, "un temps de maturation religieuse et politique sous le signe de l'intransigeantisme» (p. 244). Guiraud très tôt rompt l'équilibre entre la critique scientifique et la fidélité religieuse (p. 224). « Dans quelle mesure le goût prononcé de Jean Guiraud pour l'archéologie chrétienne participe-t-il d'un véritable intérêt scientifique ou d'une effusion de sa vive piété ? [...] on a parfois le sentiment que les catacombes constituent pour lui tout autant un lieu de recueillement et d'édification qu'un objet d'exploration ou d'étude » (p. 203). 
4 «Chrétien ombrageux et républicain de raison", il aspire à une politique de défense religieuse selon les principes et les intérêts de l'Église (p. 249). Il cherche à fonder une contre-société chrétienne. Même ses recherches d'historien sont guidées "par les attaques portées contre l'Église au temps de la République radicale» (p. 289). Il est un « historien catholique militant». L'histoire devient alors « un moyen de reconquête catholique puisque l'érudition sincère ne pourra que mettre en évidence les mérites de l'Église " selon lui (p. 291). Il participe d'un projet de "science catholique» sur le terrain de l'histoire à travers la Revue des questions historiques, qu'il codirige à partir de 1909, puis seul en 1922. Il justifie un usage apologétique, « confessionnalo-rationaliste » (p.320) de l'histoire pour établir la "vérité" catholique. Il faut montrer que le catholicisme a joué un rôle bénéfique. Parmi les constantes de son œuvre, la défense de la lutte contre l'hérésie au Moyen Âge grâce à l'Inquisition: les hérétiques sont les nihilistes de leur temps, l'Église est le rempart de la société, les attaques contre l'Église sont donc des attaques contre l'ordre établi : « La morale elle-même, dépouillée de tout caractère transcendant par une laïcité matérialiste et athée, n’a plus ni obligations ni sanctions [...]. Au milieu de ce chaos, seuls demeurent debout, les principes inébranlables du catholicisme, règles permanentes pour l'intelligence et l'action, l'individu et la société. » (Pourquoi je suis catholique, 1928) (p. 296). Le catholicisme est pour lui un système d'interprétation du monde. Ainsi il donne comme devoir au journaliste chrétien: «En Dieu, il montrera le fondement de tout édifice politique et social, solide et durable, le gardien des cités et des lois [...] la source de tous les sacrifices qui doivent [...] vivifier et féconder la société. » (La Croix, 5 janvier 1917, p. 397).

5 Ce positionnement d'apostolat laïc confère au départ à l'intellectuel catholique Guiraud une "centralité » (p.327) fondée sur un mélange d'intransigeantisme doctrinal et d'ouverture critique. «Persuadé que l'abstention des bons a fait trop souvent le succès des mauvais » écrit-il dans La Croix le 5 janvier 1917 (p. 396), il s'engage avec ardeur dans une vie militante bien remplie. Il ne conçoit l'action militante que légale (p. 349), dans une absolue obéissance à la hiérarchie ecclésiale. Membre de l'Action libérale populaire qu'il dirige dans le Doubs de 1908 à 1912, il préside l'Union des associations catholiques des chefs de famille de 1911 à 1940. Lui-même père de dix enfants, il estime que la restauration de la morale chrétienne permettra la restauration de la famille, "cellule primordiale de la société » (p.360). Cette union a pour objet de surveiller l'école publique (contrôle des manuels scolaires, refus de la coéducation des sexes et de la gémination), de promouvoir l'école catholique en obtenant la répartition proportionnelle scolaire et de lutter contre l'immoralité publique.

Depuis 1917, rédacteur en chef à La Croix, qu'il ne quitte qu'en 1939, il est un des journalistes les plus lus du quotidien. Il n'y aborde pas le religieux au sens strict. Mais il critique l'État, se méfie de l'école publique, soutient les organisations catholiques, polémique au quotidien, alerte sur l'avènement du socialisme, appelle les catholiques à la vigilance et évoque parfois des ouvrages historiques ou littéraires. Mais l'homme se marginalise, son intransigeance l'éloigne des nouveaux engagements catholiques. Le député Paul Gay lui reproche en 1922 "la répétition trop fréquente de vos attaques personnelles extrêmement violentes, et qui ont ce caractère pénible de vous ériger en juge de la sincérité des sentiments catholiques de ceux dont vous n'approuvez pas l'attitude » (p. 372). Il a alors le sentiment d'être rarement soutenu par les catholiques dans ses combats et sa solitude s'amplifie. 
7 L'ouvrage remplit donc parfaitement sa mission de resituer Jean Guiraud dans l'histoire contemporaine et de livrer des pistes pour un approfondissement de ces parcours de militants catholiques du début $\mathrm{du} \mathrm{xx}^{\mathrm{e}}$ siècle. 